\title{
PENINGKATAN PEMAHAMAN USTADZ/USTADZAH TENTANG GAYA BELAJAR SANTRI DI MASA PANDEMI MELALUI OPTIMALISASI KURIKULUM TAMAN PENDIDIKAN ALQUR'AN
}

\author{
(Pengabdian di Masjid Annur Tambakboyo, Depok, Sleman, \\ Yogyakarta)
}

\author{
Suyitno ${ }^{1}$, Yayuk Hidayah ${ }^{2}$, \\ ${ }^{1,2}$ Program Studi Pendidikan Guru Sekolah Dasar, Fakultas Keguruan dan Ilmu Pendidikan, \\ Universitas Ahmad Dahlan \\ e-mail: yayuk.hidaayah@pgsd.uad.ac.id
}

\begin{abstract}
Abstrak
Pengabdian ini bertujuan untuk meningkatkan pemahaman ustadz/ustadzah tentang gaya belajar santri di masa pandemi melalui optimalisasi kurikulum taman pendidikan alqur'an. Latar belakang pengabdian ini adalah adanya fenomena para santri yang belum dapat menyesuaikan diri dengan pembelajaran di taman pendidikan alqur'an khususnya di masa pandemi. Berdasarkan analisis kebutuhan yang tim pengabdian lakukan, terdapat kesulitan dalam beradaptasi dari para santri dengan pembelajaran di taman pendidikan alqur'an khususnya di masa pandemi. Ustadz/ustadzah di masa pandemi ini memerlukan inovasi yang lebih dalam hal penyampaian materi bagi santri, oleh sebab itu tim pengabdian melakukan pengabdian ini dengan tujuan agar ustadz/ustadzah memperoleh pemahaman mengenai gaya belajar santri yang kemudian harapannya ialah pembelajaran di taman pendidikan alqur'an dapat berjalan dengan lancar. Hasil pengabdian di analisis pengumpulan data melalui observasi, wawancara dan dokumentasi. Hasil pengabdian menunjukan bahwa terdapat beberapa penyesuaian kurikulum yang harus di lakukan oleh taman pendidikan alqur'an khususnya di masa pandemi agar pembelajaran dapat optimal yaitu perencanaan waktu dalam belajar dan materi pembelajaran. Gaya belajar santri di masa pandemi menunjukan minat yang naik turun, Sebagian besar santri merasa kurang optimal karena berkurangnya tatap muka dengan ustadz/ustadzah.
\end{abstract}

Kata kunci: Pemahaman, Taman pendidikan alqur'an, Ustadz/Ustadzah

\begin{abstract}
This service aims to improve the understanding of ustadz / ustadzah about the learning styles of students in the pandemic mass through optimizing the curriculum of the alquran education park. The background of this service is the phenomenon of students who have not been able to adjust to learning in the alquran education park, especially in the pandemic mass. Based on the analysis of the needs that the community service team carried out, there were difficulties in adapting the students to learning in the alquran education park, especially in the pandemic mass. Ustadz / ustadzah during this pandemic need more innovation in terms of delivering material to students, therefore the service team carried out this dedication with the aim that ustadz / ustadzah gain an understanding of the learning styles of students which then hopefully is that learning in the Koran education park can work. smoothly. The results of dedication in the analysis of data collection through observation, interviews and documentation. The results of this dedication show that there are several curriculum adjustments that must be done by the Alquran education park, especially in the pandemic mass so that learning can be optimal, namely planning time in learning and learning materials. The learning styles of students in the pandemic mass showed fluctuating interest. Most of the students felt that they were not optimal because of the reduced face-to-face with the ustadz / ustadzah.
\end{abstract}

Keywords: Understanding, Alqur'an Reading Garden, Ustadz / Ustadzah 


\section{PENDAHULUAN}

Kondisi pandemi yang belum usai menuntut semua elemen di TPA yang melibatkan ustadz/ustadzah dan santri serta kurikulumnya dapat beradaptasi dengan situasi dan kondisi. Hidayah et al (2020) menyatakan bahwa pada massa pandemi, terjadi perubahan gaya belajar. Fenomena yang dijumpai dilapangan, para santri TPA belum dapat menyesuaikan diri dengan pembelajaran yang sesuai dengan kondisi pandemi. Akibatnya santri merasa bosan dan kurang tertarik dalam proses pembelajaran yang monoton. Sehingga hal ini tidak sesuai dengan gaya belajar yang diharapkan santri.

Melihat kondisi di atas maka dibutuhkan peranan ustadz/ustadzah yang cerdas dan mempunyai kemampuan menyesuaikan kondisi sekitar agar mampu menciptakan lingkungan belajar yang efektif dan lebih mampu mengelola kelasnya sehingga hasil belajar akan lebih optimal. Hal ini diperkuat oleh Akmal Hawi (2014) bahwa peranan guru sebagai pengajar, yaitu guru bertugas memberikan pengajaran, menyampaikan pelajaran terkait tengan tata cara membaca Al-Qur'an yang baik dan benar seperti memberikan pemahaman terkait dengan ilmu tajwid dan ilmu Al-Qur'an lainnya.

Ustadz/ ustadzah merupakan ujung tombak dari keberhasilan suatu proses pembelajaran di TPA dan harus memberikan yang baik terhadap para santrinya. Nana Sudjana (2011) menjelaskan bahwa dalam proses pembelajaran peran guru sebagai motivator yang mampu merangsang dan memberikan dorongan untuk mendinamiskan potensi peserta didik, menumbuhkan peran aktif dan daya cipta (kreatifitas), sehingga peserta didik mau belajar terus menerus.

Disamping kemampuan ustadz/ ustadzah dalam berinovasi, juga di perlukan penyesuaikan target dan tujuan penyelenggaraan TPA. Fakhrurrazi (2018) menyatakan bahwa pembelajaran adalah suatu kombinasi yang tersusun meliputi unsur-unsur manusiawi (siswa dan guru), material (buku, papan tulis, kapur dan alat belajar), fasilitas (ruang kelas, audio visual), dan proses yang saling mempengaruhi mencapai tujuan pembelajaran.

Pembelajaran di TPA tidak cukup lagi diselenggarakan secara tradisional, berjalan monoton tanpa target yang jelas dan tidak adanya prosedur evaluasi pencapaian target yang terbukti efektif dan efisien. Sukmayadi \& Suyitno (2020) menyatakan jika dalam pembelajaran TPA memerlukan variasi. Kurikulum disusun sebagai salah satu solusi pembelajaran di masa pandemi dan sesuai kebutuhan santri.

TPA perlu mempunyai kurikulum yang menjadi acuan sebagai pedoman bagi setiap lembaga pendidikan. Dengan adanya kurikulum, maka diharapkan dalam proses pembelajaran akan mempunyai tahap-tahap dan proses serta tujuan yang pasti agar kegiatan pembelajaran sesuai dengan harapan. Kurikulum memegang peranan penting dalam proses pembelajaran, sebab berkaitan dengan penentuan arah, isi, dan proses pendidikan yang menentukan pemahaman santri. Dengan demikian, ustadz/ustadzah TPA harus mampu menyusun kurikulum khususnya di masa pandemi agar target dan tujuan pembinaan akhlak dapat tercapai lebih optimal.

\section{METODE}

Objek dalam pengabdian ini adalah Peningkatan Pemahaman Ustadz/Ustadzah Tentang Gaya Belajar Santri di masa Pandemi Melalui Optimalisasi Kurikulum Taman pendidikan alqur'an. Mitra dalam pengabdian ini adalah Ustadz/ Ustadzah Masjid Annur Tambakboyo Depok Sleman Yogyakarta, Daerah Istimewa Yogyakarta.

Pelaksanaan pengabdian ini adalah melakukan pendalaman Tentang Gaya Belajar Santri di masa Pandemi Melalui Optimalisasi Kurikulum Taman pendidikan alqur'an. Solusi dari permasalahan mitra yang ditawarkan dalam pengabdian ini adalah perencanaan waktu dalam belajar dan materi pembelajaran. Gaya belajar santri di masa pandemi menunjukan minat yang naik turun, Sebagian besar santri merasa kurang optimal karena berkurangnya tatap muka dengan ustadz/ustadzah.

Pendekatan komunikasi dilakukan agar hubungan antara ustadz/ustadzah dapat semakin dekat, khususnya di masa pandemi. Materi pelatihan di susun sedemikian rupa oleh tim pengabdian agar terjawab permasalahan yang dihadapi mitra. Materi pelatihan yang diberikan ustadz/ustadzah di susun berdasarkan permasalahan yang di hadapi mitra. Materi pelatihan adalah dalam gambar 1 berikut ini: 


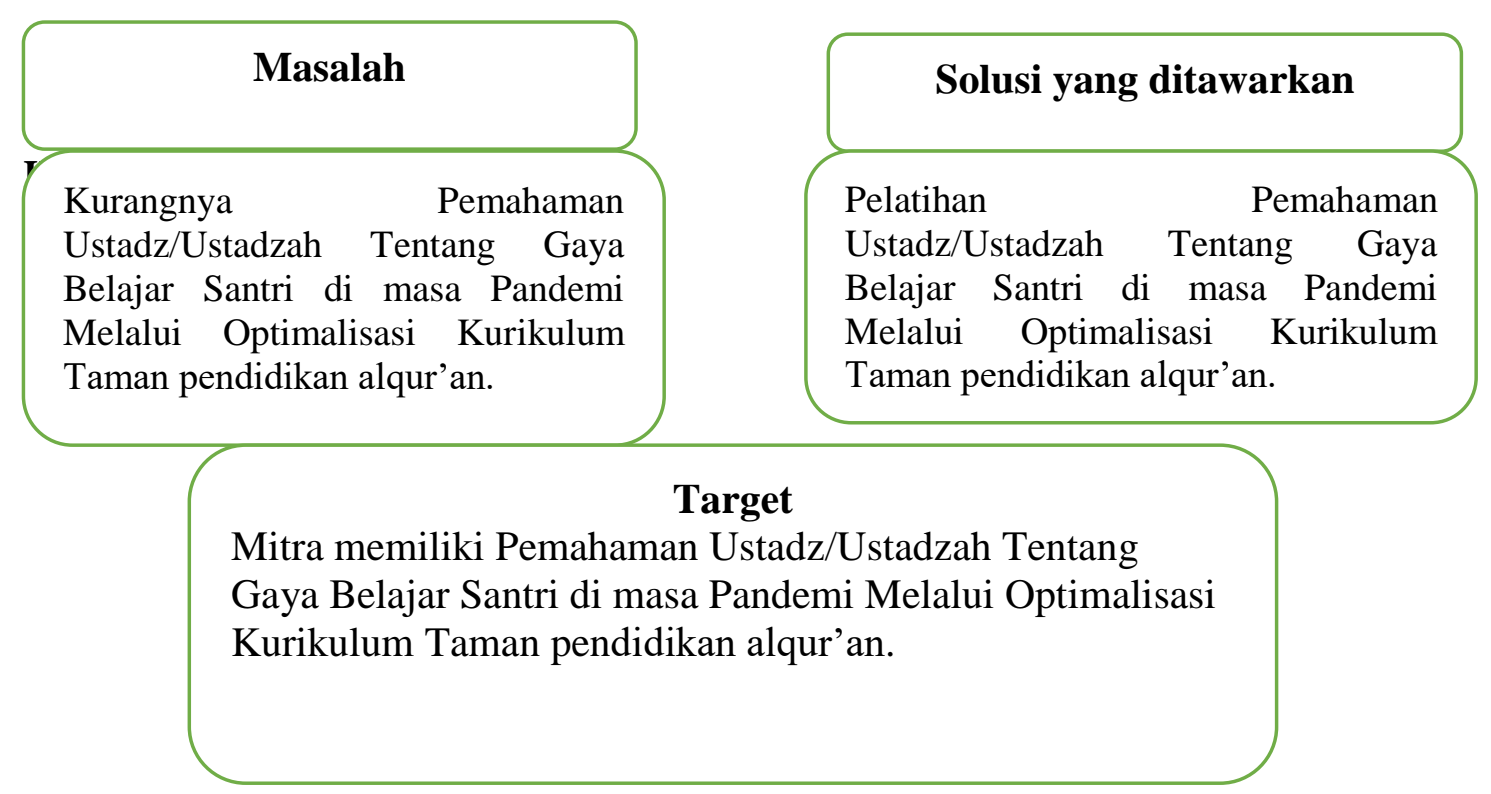

Gambar 1. Gambaran masalah dan solusi yang ditawarkan

\section{HASIL DAN PEMBAHASAN}

Penyesuaian kurikulum taman pendidikan alqur'an khususnya di massa pandemi agar pembelajaran dapat optimal sangat dibutuhkan, agar TPA dapat survive dimasa pandemi. Berdasarkan hal tersebut, maka justifikasi solusi dari permasalahan mitra mengfokuskan pada perencanaan waktu dalam belajar TPA. Hal ini disebabkan waktu dalam belajar santri massa pandemi menyesuaikan dengan situasi dan kondisi.

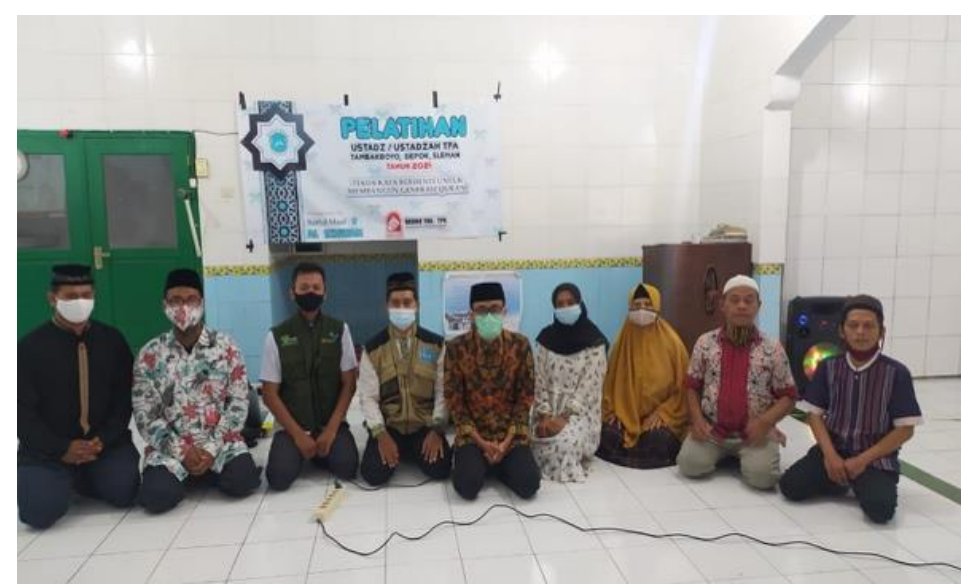

Gambar 1: Foto dengan Peserta Pengabdian

Kesulitan yang dihadapi mitra awanya adalah dalam menerima mengenai pemaknaan kurikulum. Namun setelah mitra mengalami pelatihan, mitra dapat menyesuaikan dengan dapat menentukan arah kurikulum TPA. Rayyan, Abdi, Winarsi, \& Warda (2020) menjelaskan jika kegiatan pengabdian yang efektif dapat mencapai target yang maksimal. Melalui kegiatan pengabdian ini, menunjukan kemajuan yang baik dari Ustadz/Ustadzah. Terjadi peningkatan dalam hal struktur kurikulum TPA, materi dan waktu pembelajaran di TPA.

Target pengabdian ini adalah, Mitra memiliki Pemahaman Ustadz/Ustadzah Tentang Gaya Belajar Santri di masa Pandemi Melalui Optimalisasi Kurikulum Taman pendidikan alqur'an. Melalui Optimalisasi Kurikulum, maka Ustadz/Ustadzah akan memiliki kemampuan dalam menentukan pembelajaran di Taman pendidikan alqur'an selama masa pandemi. 


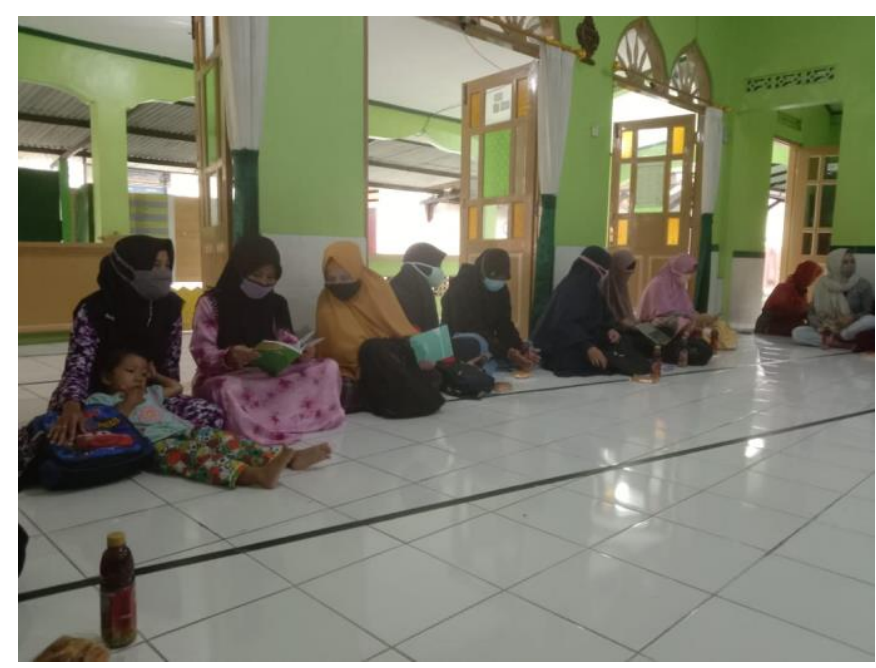

Gambar 2: Foto Peserta dalam kegiatan Pengabdian

Materi pelatiahan dilakukan secara bertahap. Mulai dari pengenalan kurikulum, materi di TPA dan waktu belajar di TPA. Kegiatan pelatiahan ini akhirnya dapat memberikan pemahaman mendalam pada Ustadz/Ustadzah dalam Menyusun kurikulum di TPA. Pengenalan kurikulum, materi di TPA bagi Ustadz/Ustadzah merupakan bagian dalam pengembangan professional. Petersen (2015) menjelaskan jika pengembangan professional dapat memprioritaskan pengajaran, dan keselarasan antara rencana pendidikan individual siswa, penilaian alternatif, dan kurikulum.

Peningkatan pemahaman ustadz/ustadzah tentang gaya belajar santri di masa pandemi melalui optimalisasi kurikulum taman pendidikan alqur'an dirasa penting. Hidayah, Suyitno, \& Retnasari (2019) menyatakan jika pemberdayaan taman pendidikan alqur'an dapat menjadi panutan dalam penanaman karakter pada santri.

Secara runtun, ustadz/ustadzah dapat memahami mengenai gaya belajar santri di masa pandemi, sehingga selanjutnya pembelajaran di taman pendidikan alqur'an selama masa pandemi dapat berjalan secara efektif.

\section{SIMPULAN DAN SARAN}

Setelah terlibat dalam beberapa kali pelatihan, dapat disimpulkan bahwa selama dilakukan pelatihan, mitra memilki semangat dalam melakukan optimalisasi kurikulum taman pendidikan alqur'an, namun mitra terbatas dalam pengetahuan. Metode pelatihan ini dianggap tepat karena dapat meningkatkan pemahaman ustadz/ustadzah tentang gaya belajar santri di massa pandemi melalui optimalisasi kurikulum taman pendidikan alqur'an. Keberlanjutan pengabdian ini adalah memberikan pengetahuan mengenai manajemen pembelajaran di taman pendidikan alqur'an khususnya di masa pandemi. Dukungan dari pemerintah setempat dan masyarakat sangat dibutuhkan dalam kegiatan pengabdian ini.

Disarankan untuk dapat melakukan pengabdian serupa di tempat lainya dan pengabdian ini terdapat tindak lanjutnya.

\section{UCAPAN TERIMA KASIH}

Tim pengabdian mengucapkan terimakasih kepada LPPM Universitas Ahmad Dahan yang telah mengizinkan tim untuk dapat melakukan pengabdian ini. Terimaksih kepada takmir Masjid Annur Tambakboyo Depok Sleman Yogyakarta, yang telah mengizinkan pelaksanaan pengabdian ini. Baitul maal Al ikhwan sebagai penyelanggara dan badan koordinasi TKA-TPA Rayon Depok serta terimaksih kepada Ustadz / Ustadzah yang telah bersedia di wawancarai.

\section{DAFTAR PUSTAKA}

Akmal Hawi. (2014). Kompetensi Guru Pendidikan Agama Islam. Jakarta: Rajawali Pers,

Hidayah, Y., Halimah, L., Trihastuti, M., Dewie, D. A., Feriandi, Y. A., \& Dianasari, D. (2020). How Did Prospective Elementary School Teacher Learn Citizenship Education during the Pandemic Covid-19 in Indonesia? IJERI: International Journal of Educational Research and Innovation, 15, 373-387. 
Hidayah, Y., Suyitno, \& Retnasari, L. (2019). Pemberdayaan Taman Pendidikan Al-Quran (TPA) Sebagai Pusat Pendidikan Karakter Religus (Pengabdian di TPQ Silastra Condong Catur,TPQ Darul Falah Maguwo Harjo Maguwo Harjo, TPA Al-Huda Caturtunggal, Yogyakarta). Loyalitas, 2(2).

Petersen, A. (2015). Perspectives of Special Education Teachers on General Education Curriculum Access: Preliminary Results. Research and Practice for Persons with Severe Disabilities, 41(1), 19-35. https://doi.org/10.1177/1540796915604835

Rayyan, W. O., Abdi, M. N., Winarsi, E., \& Warda. (2020). PENINGKATAN DAYA SAING UMKM MELALUI OPTIMALISASI PENYUSUNAN LAPORAN KEUANGAN. Jurnal Dedikasi Masyarakat, 3(3), 97 - 105.

Sukmayadi, T., \& Suyitno, S. (2020). Implementasi PPKn berbasis Nilai-nilai Islam di SD Muhammadiyah Kecamatan Depok Sleman Yogyakarta. JPK (Jurnal Pancasila Dan Kewarganegaraan), 5(1). https://doi.org/10.24269/jpk.v5.n1.2020.pp44-53 